\title{
Energy expenditure and physiological responses during indoor rock climbing
}

\author{
Christine M Mermier, Robert A Robergs, Susie M McMinn, Vivian H Heyward
}

\begin{abstract}
Objectives-To report the physiological responses of indoor rock climbing. Methods-Fourteen experienced climbers (nine men, five women) performed three climbing trials on an indoor climbing wall. Subjects performed three trials of increasing difficulty: $(a)$ an easy $90^{\circ}$ vertical wall, (b) a moderately difficult negatively angled wall $\left(106^{\circ}\right)$, and $(c)$ a difficult horizontal overhang $\left(151^{\circ}\right)$. At least 15 minutes separated each trial. Expired air was collected in a Douglas bag after four minutes of climbing and heart rate (HR) was recorded continuously using a telemetry unit. Arterialised blood samples were obtained from a hyperaemised ear lobe at rest and one or two minutes after each trial for measurement of blood lactate.
\end{abstract}

Results-Significant differences were found between trials for $H R$, lactate, oxygen consumption $\left(\mathrm{Vo}_{2}\right)$, and energy expenditure, but not for respiratory exchange ratio. Analysis of the $\mathrm{HR}$ and $\mathrm{Vo}_{2}$ responses indicated that rock climbing does not elicit the traditional linear HR$\mathrm{Vo}_{2}$ relationship characteristic of treadmill and cycle ergometry exercise. During the three trials, HR increased to $74-85 \%$ of predicted maximal values and energy expenditure was similar to that reported for running at a moderate pace (8-11 minutes per mile).

Conclusions-These data indicate that indoor rock climbing is a good activity to increase cardiorespiratory fitness and muscular endurance. In addition, the traditional HR-Vo $\mathrm{O}_{2}$ relationship should not be used in the analysis of this sport, or for prescribing exercise intensity for climbing.

(Br F Sports Med 1997;31:224-228)

Keywords: rock climbing; caloric expenditure; heart rate; oxygen consumption

Center for Exercise and Applied Human Physiology, University of New Mexico, Albuquerque, NM 87131, USA

C M Mermier

R A Robergs

S M McMinn

V H Heyward

Correspondence to: Dr Mermier.

Accepted for publication 26 February 1997 due to increased participation in climbing on short rock walls and indoor climbing, employing strenuous gymnastic type movements.
Traditionally, rock climbing was one aspect of mountaineering. Mountaineering usually involves multiday summit attempts of high mountains that combines hiking, scrambling, and technical climbing on rock and ice while carrying all necessary gear in a pack.

There is now an international circuit of climbing competitions that take place on indoor climbing walls. Many indoor climbing gymnasiums have been constructed in the United States and Europe using specially fabricated modular holds which enable climbers to train regardless of the season. Climbing walls are set up to accommodate varying skill levels by modifying wall angles and hold size.

Despite the rising popularity of this sport, to date there are few studies reporting physiological responses during rock climbing. Much of the research on mountaineering has focused on physiological changes at high altitude. ${ }^{2-4}$ In addition, some studies have measured physiological responses during exercise using either a Versaclimber ${ }^{56}$ or climbing treadmill ${ }^{78}$ to simulate climbing. Although Williams et at reported heart rate (HR) and plasma catecholamine responses during ascents of short rock faces, the angle of the ascent and difficulty of the climbs were not specified. One recent study by Billat $e t a l^{10}$ examined the change in whole body oxidative metabolism during climbing on modular walls. They used four experienced climbers to compare $\mathrm{Vo}_{2}$ max measured during running and upper body pulling with that measured while climbing two difficult climbing courses.

Thus the purpose of the present study was to measure physiological responses to indoor rock climbing during easy, moderately difficult, and difficult climbs. Knowledge of metabolic and cardiovascular responses to various activities is useful for exercise prescription, to evaluate the safety of activities for various populations, to code more precisely for activity self-reports, and to assess nutritional needs and training methods. In addition, we sought to provide a base of descriptive measures that can be utilised to generate more complex physiological questions for the sport in future research studies. We hypothesised that there would be significant differences in the $\mathrm{HR}$, oxygen consumption $\left(\mathrm{VO}_{2}\right)$, blood lactate, energy expenditure (EE), and respiratory exchange ratio (RER) for the three levels of climbing difficulty.

\section{Methods}

Fourteen climbers (nine men, five women) volunteered for the study. Subjects responded 
to recruitment posters placed at a local indoor climbing facility. They were experienced climbers who were able to complete three rock climbing courses of increasing difficulty taking five minutes each.

Volunteers reported to the climbing facility with their climbing harness, shoes, and chalk bag. All subjects refrained from exercising at least 12 hours before testing, and eating at least two hours before testing. Comprehensive health history questionnaires showed that all subjects were free from injury and disease. Informed consent was obtained from each participant before testing.

Subjects were weighed in shorts and T-shirts without shoes on a calibrated medical balance beam scale (Health-o-meter, Bridgeview, IL, USA) to the nearest $0.1 \mathrm{~kg}$. Gear weight (climbing shoes, harness, chalk bag, and data collection instrumentation) was measured on the same medical balance beam scale, and averaged $3.1 \mathrm{~kg}$ with less than $0.5 \mathrm{~kg}$ variation between subjects. Total weight was calculated by adding gear weight to body weight (since this is the weight that was supported during climbing). Height was measured to the nearest $0.5 \mathrm{~cm}$.

All trials for each subject were performed on the same day. Before any data collection, subjects were allowed to practice climbing while wearing the data collection apparatus. The preparatory time was also used to ensure that all apparatus was properly and securely fitted. Before each trial, subjects performed a standardised timed five minute warm up including stretching and easy climbing. Subjects then performed three climbs of increasing difficulty on $6.35 \mathrm{~m}$ walls, each lasting five minutes. Difficulty was increased by setting climbs on walls with steeper angles and with smaller and fewer handholds and footholds. Arrangements were made with the climbing gym staff to refrain from moving any holds on the three courses until the study was completed. Subjects were inactive for 15 to $20 \mathrm{~min}$ utes between each climbing trial. To ensure that a true resting baseline condition was achieved, succeeding trials did not begin until $\mathrm{HR}$ returned to resting pre-exercise values.

The three climbs were performed in ascending order of difficulty according to the Yosemite decimal system. ${ }^{11}$ The first climb was an easy $90^{\circ}$ vertical wall, rated 5.6. The second climb was a moderately difficult negatively angled wall $\left(106^{\circ}\right)$, rated 5.9. The last climb was a difficult horizontal overhang of $151^{\circ}$, rated $5.11+$. Top ropes were used for safety reasons; however, subjects climbed up and down the walls continuously without aid from any rope tension. Subjects who lost their grip and were forced to momentarily fall on the rope were allowed to continue, but were not allowed to rest. Two female rock climbers were unable to finish the most difficult climb without rest. None of their data were included in any analyses. Subjects were instructed to climb at their normal pace but were told to minimise isometric holding. There were a similar number of ascents and descents for all subjects (no more than two laps difference).
Expired air was collected during the last minute of each climbing trial using a Douglas bag attached to the climbing harness. A face mask (M 1410, Hans Rudolph, Kansas City, MO, USA) covering the nose and mouth was attached to $1 \mathrm{~m}$ of low resistance tubing connected to a 200 litre capacity Douglas bag. Subjects wore this apparatus throughout each climb. A two way valve was opened during the last minute of each trial to collect expired air into the Douglas bag. The valve was opened as the subject approached the lowest footholds, and the gas sample was obtained without delaying the progress of the climber. The valve was closed immediately after the subject returned to ground. The total collection time was recorded for the calculation of volume of expired air (VE).

VE was measured using a flow meter (Singer, Philadelphia, PA, USA). Fractions of oxygen and carbon dioxide were measured with paramagnetic and infrared analysers respectively (Erich Jaeger, Hoechberg, Germany), which were calibrated with gases of known percentages. $\mathrm{Vo}_{2}, \mathrm{VCO}_{2}$, and RER were calculated and $\mathrm{EE}$ was calculated using the non-protein RER kJ equivalents. All gas samples were analysed within one hour of data collection. HR was measured continuously and stored in memory using a small telemetry unit (CIC Heartwatch, Hempstead, NY, USA). The transmitter was placed on the chest and attached to two standard electrocardiograph electrodes. Electrodes were used in place of the chest strap provided by the manufacturer to prevent constriction of the chest which may have restricted breathing. The receiver was attached to the subject's wrist and was angled so that researchers could easily read the digital display to ensure that the telemetry unit was functioning properly during the trials. The average $H R$ from the final minute of each trial was used for analysis.

Blood samples from the ear lobe were obtained before the first climbing trial, and after each climbing trial to determine resting and exercising blood lactate concentrations. Before any other data collection, a topical heating agent (Balsem Gosok, Tangerang, Indonesia) was rubbed on to both ear lobes to stimulate blood flow to the area. After 15 minutes of seated rest, a sterile lancet was used to make a small incision into the base of one ear lobe, and $30 \mu \mathrm{l}$ arterialised blood was collected into a heparinised capillary tube. The blood was then transferred to a tube prepared with $100 \mu 17 \%$ perchloric acid. Only one resting blood sample was taken to lessen the number of ear punctures required. Post-exercise blood samples were drawn one or two minutes after each climbing trial to allow time for the subject to remove the apparatus and sit down after climbing. Research shows that during these initial minutes of recovery, lactate concentrations are maximal or remain elevated for this type of exercise. $^{12-14}$ Lactate was analysed by an enzymic spectrophotometric technique. All samples were assayed in duplicate.

Each subject was hydrostatically weighed ${ }^{15}$ at residual volume ${ }^{16}$ using standard procedures 
Table 1 Descriptive characteristics of rock climbers. Data are means (SD)

\begin{tabular}{lllll}
\hline Group & Age (years) & Weight (kg) & Height (cm) & Body fat (\%) \\
\hline Men $(\mathrm{n}=9)$ & $26.7(7.8)$ & $66.3(6.1)$ & $175.5(5.6)$ & $6.8(2.6)$ \\
Women $(\mathrm{n}=5)$ & $32.4(9.7)$ & $54.5(3.9)$ & $164.7(5.6)$ & $14.6(2.3)$ \\
Combined & $28.4(8.6)$ & $62.3(8.3)$ & $170.7(8.7)$ & $10.2(4.6)$ \\
\hline
\end{tabular}

within a week of the climbing trials. Body density was converted to percentage body fat using the equation of Brozek et al. ${ }^{17}$

Independent $t$ tests were used to determine whether or not there were gender differences for each of the dependent variables $\left(\mathrm{HR}, \mathrm{Vo}_{2}\right.$, lactate, $\mathrm{EE}, \mathrm{VE}, \mathrm{VCO}_{2}$, and $\left.\mathrm{RER}\right)$. No significant differences $(P>0.05)$ were found. Therefore data for the men and women were pooled for all subsequent analyses. One way analysis of variance with repeated measures was used to compare the $\mathrm{HR}, \mathrm{Vo}_{2}$, lactate, $\mathrm{EE}, \mathrm{VE}, \mathrm{VcO}_{2}$, and RER responses across the three climbing trials. Scheffé post hoc tests identified which means differed significantly from each other. $P \leqslant 0.05$ was used to define statistical significance.

\section{Results}

Table 1 summarises the physical characteristics of the subjects. Table 2 gives the average values for $\mathrm{HR}$, lactate, $\mathrm{VE}, \mathrm{VCO}_{2}$, and $\mathrm{EE}$ for each climbing trial. The main effect of the trials was significant for $\mathrm{HR}(F(2,26)=37.43, \mathrm{P}=$ $0.0001)$, lactate $(F(3,39)=44.242, \mathrm{P}=$ $0.0001)$, VE $(F(2,26)=3.657, \mathrm{P}=0.0399)$, $\mathrm{VCO}_{2}(F(2,26)=4.801, \mathrm{P}=0.0168)$, and EE $(F(2,26)=3.947, P=0.0318)$. Scheffé comparisons for $\mathrm{HR}$ and lactate indicated that the average $H R$ and post-exercise lactate for all trials differed significantly from each other. $\mathrm{Vo}_{2}, \mathrm{VE}, \mathrm{VcO}_{2}$, and lactate values for the difficult trial were significantly larger than for the easy trial. Also, the average resting lactate differed significantly from the post-exercise lactate levels for all three climbing trials. The average $\mathrm{EE}$ for the easy trial $(0.622 \mathrm{~kJ} / \mathrm{kg}$ per $\mathrm{min}$ or $38.9 \mathrm{~kJ} / \mathrm{min}$ ) was significantly less than that for the difficult trial $(0.844 \mathrm{~kJ} / \mathrm{kg}$ per min or $52.7 \mathrm{~kJ} / \mathrm{min}$ ). There was no significant difference for RER across the trials.

\section{Discussion}

HEART RATE RESPONSES

Mean HR during three climbing trials increased to 142,155 , and 163 beats/min for the easy, moderate, and difficult trials respectively. The means correspond to $74-85 \%$ of predicted

Table 2 Comparison of the physiological variables for easy, moderate, and difficult climbing trials $(n=14)$. Data are means $(S D)$

\begin{tabular}{|c|c|c|c|}
\hline Variable & Easy (5.6) & Moderate (5.9) & Difficult $(5.11+)$ \\
\hline $\begin{array}{l}\mathrm{HR} \text { (beats/min) } \\
\mathrm{Vo}_{2}(\mathrm{ml} / \mathrm{kg} \mathrm{per} \mathrm{min}) \\
\mathrm{RER}\left(\mathrm{CO}_{2} / \mathrm{O}_{2}\right) \\
\mathrm{EE}(\mathrm{kJ} / \mathrm{kg} \mathrm{per} \mathrm{min}) \\
\mathrm{VE}(\mathrm{litres} / \mathrm{min}) \\
\mathrm{VCO}_{2}(\mathrm{ml} / \mathrm{kg} \mathrm{per} \mathrm{min}) \\
\text { Lactate }(\mathrm{mmol} / \mathrm{l})\end{array}$ & $\begin{array}{l}142(19)^{\star} \dagger \\
20.7(8.1) \\
0.81(0.06) \\
0.622(0.393) \\
32.6(16.4) \\
17.4(6.2) \\
1.64(0.63)^{\star} \dagger\end{array}$ & $\begin{array}{l}155(15)^{\star} \ddagger \\
21.9(5.3) \\
0.84(0.09) \\
0.665(0.318) \\
39.8(14.5) \\
19.2(4.8) \\
2.40(0.68)^{\star} \ddagger\end{array}$ & $\begin{array}{l}163(15) \dagger \ddagger \\
24.9(4.9) \ddagger \\
0.86(0.11) \\
0.844(0.309) \ddagger \\
44.3(14.5) \ddagger \\
22.3(4.2) \dagger \ddagger \\
3.20(0.97) \dagger \ddagger\end{array}$ \\
\hline
\end{tabular}

$\overline{\mathrm{HR}}=$ heart rate; $\mathrm{Vo}_{2}=$ oxygen consumption; RER = respiratory exchange rate; $\mathrm{EE}=$ energy expenditure; $\mathrm{VCO}_{2}=$ carbon dioxide production.

$\star \mathrm{P}<0.05 v$ difficult.

$+\mathrm{P}<0.05 v$ moderate.

$\ddagger P<0.05 v$ easy. maximal HR (220 - age). These results were similar in range to, but different in degree of change across trials from, those reported by Watts $e t a l^{\beta}$ for five climbing trials ranging from 80 to $102^{\circ}$ angles using a Treadwall (Brewers Ledge, Jamaica Plain, MA, USA) climbing treadmill. A direct comparison between climbing trials for these two studies is difficult since a rating system such as the Yosemite decimal system was not used by Watts et al. ${ }^{8}$ However, an adequate comparison can be made using angles of the climbing trials. In their study, the average HR increased from 156 beats $/ \mathrm{min}\left(80^{\circ}\right.$ angle) to 171 beats $/ \mathrm{min}\left(91^{\circ}\right.$ angle) but plateaued between 91 and $102^{\circ}$ (171-173 beats/min). The failure of the HR to increase across the last three trials could be attributed to the small difference in angle between the trials. In their study, there was an average of $6^{\circ}$ increase in angle with each successive trial. This may not have been a large enough change to observe a HR difference, especially at the steeper angles.

Billat et $a l^{10}$ measured HR during two climbs rated $7 \mathrm{~b}$ (French rating system), which roughly corresponded in difficulty to the 5.11+ (Yosemite decimal system) trial. Average HR was 176 and 159 beats/min for the first and second trials respectively, which corresponded to an average of 85.5 and $77 \%$ of the subjects' running maximal HR measured during a treadmill test.

Regardless of angle or difficulty of climbing trials, the results from the present study and the other studies ${ }^{810}$ show relatively high HR responses during climbing exercise. This increase in HR during rock climbing can be explained in part by the use of intermittent isometric muscular contractions $(37 \%$ of total ascent duration $)^{10}$ and the reliance on the arms as a major muscle group during more difficult climbing trials.

Research has shown that isometric contractions produce a disproportionate increase in $\mathrm{HR}$ relative to $\mathrm{Vo}_{2}$ at any level of work. ${ }^{18-20} \mathrm{It}$ has also been shown that the magnitude of the cardiovascular response to isometric contraction is directly influenced by the size of the contracting muscle mass. ${ }^{19}$ Another factor that may be important in the understanding of $H R$ responses during rock climbing is arm position. During rock climbing, the arms are often held above the level of the heart. Åstrand $e t a l^{1}$ reported greater increases in lactate, $H R$, and blood pressure for carpenters nailing with the arms in a vertical position above the head compared with nailing at waist level. Although the position of the arms may be anywhere from level with the feet to fully extended overhead during rock climbing, much of the time the arms are above the level of the heart.

Psychological stress may also be a consideration in the understanding of $\mathrm{HR}$ responses during rock climbing. Williams et al measured $\mathrm{HR}$ and plasma catecholamine responses during rock climbing. Subjects undertook two climbs on the same day. The first trial was carried out after the ingestion of a placebo tablet, and the second after ingesting oxprenolol (a $\beta$ blocker). HR rose during both trials, with mean 
(SD) maximum HR of 166 (20) beats/min during the placebo trial, and 120 (10) beats/ min for the oxprenolol trial. Plasma catecholamine levels rose only during the placebo trial. Based on these physiological measures, the authors concluded that increases in HR are due more to anxiety or fear of falling than to physical exertion during difficult rock climbing on small cliffs. Billat et $a l^{10}$ also addressed this issue by allowing their four subjects to train extensively on the routes before the trials to minimise psychological stress during climbing.

During the present study, psychological stress was not measured, but is assumed to be limited somewhat by testing experienced climbers and by the use of safety ropes during climbing trials. Nevertheless, owing to the observation that some fear of heights seems to be common, the comments of Williams et al cannot be discounted.

\section{$\mathrm{VO}_{2}$ RESPONSES}

The results of the present study show a marked increase in $\mathrm{HR}$ without a concomitant increase in $\mathrm{Vo}_{2}$ across the trials. $\mathrm{Vo}_{2}$ values were 20, 22, and $25 \mathrm{ml} / \mathrm{kg}$ per min for the easy (5.6), moderate (5.9), and difficult $(5.11+)$ trials respectively. Billat et $a l^{10}$ reported average $\mathrm{Vo}_{2}$ values of 25.9 and $20.6 \mathrm{ml} / \mathrm{kg}$ per $\min$ ( 46 and $37.5 \%$ of subjects' measured running $\mathrm{Vo}_{2} \mathrm{max}$ )for two climbs rated $7 \mathrm{~b}$. Watts et $a l^{\beta}$ also reported low $\mathrm{VO}_{2}$ values compared with corresponding $\mathrm{HR}$ values during Treadwall climbing. The $\mathrm{VO}_{2}$ values were slightly higher $(20.9-31.7 \mathrm{ml} / \mathrm{kg}$ per min) compared with those observed in the present study.

Data from these three studies show relatively low $\mathrm{Vo}_{2}$ values compared with corresponding $\mathrm{HR}$ levels. These data indicate that the relationship between $\mathrm{HR}$ and $\mathrm{Vo}_{2}$ appears to be non-linear during rock climbing. Although $\mathrm{HR}$ increased progressively as a function of difficulty, $\mathrm{Vo}_{2}$ remained constant across the trials. This response to rock climbing differs from the typical linear $\mathrm{HR}-\mathrm{Vo}_{2}$ relationship demonstrated for exercise modes such as running and cycling. ${ }^{72}$

Isometric work elicits a disproportionate rise in $\mathrm{HR}$ in relation to $\mathrm{Vo}_{2}$. Although care was taken in the present study to instruct subjects to minimise isometric holding during the climbing trials, isometric work could not be eliminated. Climbing requires combined arm and leg work, characterised by dynamic moves, interspersed with periods of isometric muscular contractions. This pattern alternates between the legs and arms, usually allowing two to three points of contact on the holds for support while moving. In general, on easier climbs, the legs do more of the work, similar to climbing a ladder. However, as climbs become more difficult, the importance of arm work and isometric contraction increases. Although the amount of isometric work was not measured in this study, it was observed that climbing speed slowed and isometric holding increased with the difficulty of the climbing trial.

As mentioned previously, Billat et $a l^{10}$ noted that isometric work represented more than one third of the total climbing time for two difficult climbing routes, as determined by video analysis of the four subjects on the climbing routes. Thus the disproportionate use of the smaller upper body musculature combined with intermittent isometric work during difficult climbs may explain why $\mathrm{Vo}_{2}$ did not increase in proportion to $\mathrm{HR}$ during the more difficult climbing trials.

\section{LACTATE RESPONSES}

The post-exercise lactate concentrations increased significantly across the climbing trials from $1.28 \mathrm{mmol} / 1$ at rest to $1.64,2.40$, and $3.20 \mathrm{mmol} / 1$ for the easy, moderate, and difficult climbing trials respectively. These data, along with increased RER from 0.81 to 0.86 , reflect the increased physiological demands of the moderate and difficult climbs as compared with the easy climb, as well as an increased reliance on glycolytic metabolism as the climbing trials increased in difficulty.

Post-exercise lactate concentrations measured during the present study were lower than those reported for simulated climbing, ${ }^{8}$ arm plus leg ergometry, ${ }^{23}$ overhead nailing, ${ }^{21}$ climbing modular walls, ${ }^{10}$ and treadmill running. Subjects reported forearm fatigue without concomitant leg fatigue after the moderate and difficult climbing trials. During the trials on steeper terrain, most of the lactate production may have been in the forearm, a relatively small muscle mass.

Given the high HR values during the three trials, lactate concentrations were lower than expected. Two possible explanations as to why post-exercise lactate did not increase as expected during the three climbing trials are the effects of dilution caused by the large central venous blood volume and impaired lactate clearance during isometric contraction. Uptake of circulating lactate by non-exercising muscle may be a factor as well. This point is addressed in a study by Richter et $a l^{4}$ in which lactate concentration was measured during knee extension exercise, with and without accompanying arm cranking. The authors concluded that both exercising and non-exercising muscle is capable of lactate uptake and removal from the circulation.

Lower lactate concentrations were measured during the present study compared with values during Treadwall climbing and climbing on high-angled artificial walls. Billat et $a l^{10}$ reported 5.75 and $4.3 \mathrm{mmol} / \mathrm{l}$ after climbing two difficult (7b) routes, lasting an average of 3.45 minutes. Also, Watts et at observed mean lactate levels of $3.6 \mathrm{mmol} / 1$ for the lowest angle to $5.9 \mathrm{mmol} / \mathrm{l}$ for the steepest angle.

\section{ENERGY EXPENDITURE}

In the present study, the mean EE values for the three climbing trials were $0.622,0.665$, and $0.844 \mathrm{~kJ} / \mathrm{min}$ per $\mathrm{kg}(38.9,41.4$, and 52.7 $\mathrm{kJ} / \mathrm{min}$ ) respectively, for a mean body weight of $62.3 \mathrm{~kg}$. These values reflect energy expenditures similar to those for running on a horizontal surface at speeds of 10:30, 10:15, and 8:00 minutes per mile respectively. ${ }^{25}$

Watts $e t a l^{\beta}$ reported average EE ranging from 43.5 to $46.8 \mathrm{~kJ} / \mathrm{min}$ for five climbing trials 
on the Treadwall, with the highest EE attained at the $86^{\circ}$ angle. Although they found no significant differences in $\mathrm{EE}$ with increasing climbing angle, our data show the average EE during the easy trial was significantly less than during the difficult trial. Again, this disparity may be explained by differences in angle and difficulty of the climbing trials between the two studies. The larger average difference in angles between successive trials in the present study may explain why the EE increased across trials, while it remained constant during the Treadwall study. Although the average increase in RER was not significant in the present study across trials, there was a tendency for RER to rise as the climbing trials increased in difficulty.

\section{Conclusions}

Indoor rock climbing expends energy at a relatively high rate. The increase in $\mathrm{Vo}_{2}$ for this activity was similar to moderate paced walking, and mean HR increased to $74-85 \%$ of age predicted maximal values. Our data indicate that indoor rock climbing requires moderate levels of physical exertion and therefore may be a good activity for increasing cardiorespiratory fitness and muscular endurance, especially in a previously sedentary population.

Data collected during three climbing trials showed significant increases in $\mathrm{HR}$ and lactate but only modest increases in $\mathrm{Vo}_{2}$. Given that isometric muscular contraction and raising the arms above the level of the heart are often necessary during climbing, the traditional $\mathrm{HR}-\mathrm{Vo}_{2}$ relationship should not be used in the analysis of this sport or for prescribing exercise intensity for climbing activities. Also, the significant differences in HR and lactate between three increasingly difficult climbing trials (and significant difference between the easy and difficult trials for $\mathrm{Vo}_{2}, \mathrm{VCO}_{2}, \mathrm{VE}$, and EE) indicate that the ratings system currently used by climbers discriminates well between easy, moderate, and more difficult climbs.

Additional research is needed to assess the amount of isometric and dynamic movement during climbing, the relative use of aerobic and anaerobic metabolic pathways for energy production during climbing, as well as the contribution of muscle strength and endurance to rock climbing performance.

The authors would like to thank Craig Keaty for his invaluable assistance in subject recruitment, data collection, and access to the climbing wall facility. We would also like to thank Sharon Griffin and Jim Milani for their help in preparing the manuscript.
1 Smoot J. Is climbing really dangerous? Rock EN Ice 1993; 58:52-8.

2 Kramer P, Drinkwater B. Women on Annapurna. Physician Sports Medicine 1980;8:93-9.

3 Oelz O, Howald H, di Prampero PE, Hoppeler H, Claassen RJ, Bühlmann A, et al. Physiological profile of world-class high-altitude climbers. $\mathcal{F}$ Appl Physiol 1986;60:1734-42.

4 Watts PB, Martin DM, Schmeling MH, Silta BC, Watts AG. Exertional intensities and energy requirements of technical mountaineering at moderate altitude. 7 Sports Med Phys mountaineering at moder.

5 Ballor DL, Becque MD, Katch VL. Metabolic responses during hydraulic resistive simulated climbing. Res $Q$ Exerc Sport 1988;59:165-8.

6 Brahler CJ, Blank SE. Versa Climbing elicits higher $\mathrm{VO}_{2 \max }$ than does treadmill or rowing ergometry. Med Sci Sports Exerc 1995;27:249-54.

7 Watts PB, Drobish KM, Deaur KL, Gibbons TP, Ringheim SD, Sulentic JE. Physiological comparison between simulated rock climbing and treadmill running at the same heart rate. Med Sci Sports Exerc 1993;25:S81.

8 Watts PB, Drobish KM, Ringheim S. Physiological responses and energy costs of rock climbing at various difficulty levels. Physiologist 1992;35:233.

9 Williams ES, Taggart P, Carruthers M. Rock climbing: observations on heart rate and plasma catecholamine concentrations and the influence of oxprenolol. Brf Sports Med centrations and

10 Billat V, Palleja P, Charlaix T, Rizzardo P, Janel N. Energy specificity of rock climbing and aerobic capacity in competitive sport rock climbers. $\mathcal{f}$ Sports Med Phys Fitness 1995:35:20-4.

11 Graydon D, editor. Mountaineering: the freedom of the hills. 5th ed. Seattle: The Mountaineers, 1992:430-2.

12 Belcastro AN, Bonen A. Lactic acid removal rates during controlled and uncontrolled recovery exercise. $\mathcal{F} \mathrm{Appl}$ Phys 1975;39:932-6.

13 Wahren J. Quantitative aspects of blood flow and oxygen uptake in the human forearm during rhythmic exercise. Acta Physiol Scand 1966;67:S193.

14 Dodd S, Powers SK, Callender T, Brooks E. Blood lactate disappearance at various intensities of recovery exercise. $\mathcal{F}$ Appl. Physiol 1984;57:1462-5.

15 Bonge D, Donelly JE. Trials to criteria for hydrostatic weighing at residual volume. Res $Q$ Exerc Sport 1989;60: 176-9.

16 Motley HL. Comparison of a simple helium closed method with oxygen circuit method for measuring residual air American Review of Tuberculosis and Pulmonary Disease 1957;76:601-15.

17 Brozek J, Grande F, Anderson JT, Keys A. Densiometric analysis of body composition: revision of some quantitative assumptions. Ann NY Acad Sci 1963;110:113-40.

18 Lind AR, Taylor SH, Humphreys PW, Kennelly BM, Donald KW. The circulatory effects of sustained voluntary muscle contraction. Clin Sci 1964;27:229-44.

19 Mitchell JH, Schibye B, Payne FC III, Saltin B. Responses of arterial blood pressure to static exercise in relation to of arterial blood pressure to static exercise in relation to muscle mass, force development
activity. Circ Res 1981;48:170-5.

20 Seals DR, Washburn RA, Hanson PG, Painter PL, Nagle FJ. Increased cardiovascular response to static contraction of larger muscle groups. F Appl Physiol 1983;54:434-7.

21 Åstrand I, Guharay A, Wahren J. Circulatory responses to arm exercise with different arm positions. F Appl Physio 1968;25:528-32.

22 Wyndham $\mathrm{CH}$. Submaximal tests for estimating maximum uptake. Can Med Assoc $\mathcal{F}$ 1967;96:736-45.

23 Secher NH, Ruberg-Larson N, Binkhorst RA, BondePeterson F. Maximal oxygen uptake during arm crankin and combined arm plus leg exercise. $\mathcal{f}$ Appl Physiol 1974;36:515-18.

24 Richter EA, Kienes B , Saltin B, Christensen NJ, Savard G. Skeletal muscle glucose uptake during dynamic exercise in humans: role of muscle mass. Am $\mathfrak{f}$ Physiol 1988;254:E55561 .

25 Passmore R, Durnin JVGA. Human energy expenditure. Physiol Rev 1955;35:801-40. 